\title{
NF-кB inhibition is associated with OPN/MMP-9 downregulation in cutaneous melanoma
}

\author{
CLAUDIO GUARNERI ${ }^{1}$, VALENTINA BEVELACQUA ${ }^{2}$, JERRY POLESEL $^{3}$, LUCA FALZONE ${ }^{2}$, \\ PATRIZIA S. CANNAVÒ ${ }^{1}$, DEMETRIOS A. SPANDIDOS ${ }^{4}$, GRAZIA MALAPONTE $^{2 *}$ and MASSIMO LIBRA ${ }^{2 *}$ \\ ${ }^{1}$ Department of Clinical and Experimental Medicine, Section of Dermatology, University of Messina, I-98125 Messina; \\ ${ }^{2}$ Department of Biomedical and Biotechnological Sciences, Section of General and Clinical Pathology and Oncology, \\ University of Catania, I-95124 Catania; ${ }^{3}$ Unit of Cancer Epidemiology, CRO Aviano National Cancer Institute, IRCCS, \\ I-33081 Aviano, Italy; ${ }^{4}$ Laboratory of Clinical Virology, Medical School, University of Crete, Heraklion 71003, Greece
}

Received October 3, 2016; Accepted December 20, 2016

DOI: 10.3892/or.2017.5362

\begin{abstract}
The development of cutaneous melanoma is influenced by genetic factors, including BRAF mutations and environmental factors, such as ultraviolet exposure. Its progression has been also associated with the involvement of several tumour microenvironmental molecules. Among these, nuclear factor- $\kappa \mathrm{B}(\mathrm{NF}-\kappa \mathrm{B})$ has been indicated as a key player of osteopontin (OPN) and matrix metalloproteinase-9 (MMP-9) activation. However, whether NF- $\kappa \mathrm{B}$ plays a role in the development and progression of melanoma in association with the OPN/MMP-9 axis according to the BRAF ${ }^{\mathrm{V} 600 \mathrm{E}}$ mutation status has not been investigated in detail to date. Thus, in the present study, in order to shed light on this matter, 148 patients with melanoma and 53 healthy donors were recruited for the analysis of OPN, MMP-9 and NF- $\kappa$ B. Significantly higher circulating levels of OPN and MMP-9 were observed in the patients with melanoma when compared to the healthy donors. Similar data were obtained for NF- $\kappa$ B p65 activity. The OPN levels did not differ significantly between melanomas with or without $\mathrm{BRAF}^{\mathrm{V} 600 \mathrm{E}}$ mutation. However, as regards $\mathrm{NF}-\kappa \mathrm{B}$ and MMP-9, significant differences were observed between the melanomas with or without BRAF ${ }^{\mathrm{V} 600 \mathrm{E}}$ mutation. To determine whether NF- $\kappa \mathrm{B}$ inhibition is associated with a decrease in the levels of OPN and MMP-9, peripheral blood mononuclear cells from 29 patients with melanoma were treated with the NF- $\kappa B$ inhibitor, dehydroxymethylepoxyquinomycin (DHMEQ),
\end{abstract}

Correspondence to: Professor Massimo Libra, Department of Biomedical and Biotechnological Sciences, Section of General and Clinical Pathology and Oncology, University of Catania, 83 Via Androne, I-95124 Catania, Italy

E-mail:mlibra@unict.it

*Joint senior authorship

Key words: nuclear factor- $\kappa \mathrm{B}$, cutaneous melanoma, matrix metalloproteinase-9, osteopontin with or without OPN. As expected, the inhibition of $\mathrm{NF}-\kappa \mathrm{B}$ induced a marked decrease in both the OPN and MMP-9 levels. Furthermore, the decrease in MMP-9 levels was higher among melanomas harbouring the $\mathrm{BRAF}^{\mathrm{V} 600 \mathrm{E}}$ mutation. Overall, our data suggest that the activation of MMP-9 is associated with the $\mathrm{BRAF}^{\mathrm{V} 600 \mathrm{E}}$ mutation status. Furthermore, such an activation is mediated by $\mathrm{NF}-\kappa \mathrm{B}$, suggesting its role as therapeutic target in patients with melanoma.

\section{Introduction}

The incidence of cutaneous melanoma is increasing $(1,2)$. Although much progress has been made in terms of immuno- and chemotherapy, the mortality rate for patients with melanoma remains very high, as it is a very aggressive disease $(3,4)$. Cutaneous melanoma is influenced by genetic and environmental factors.

The dysregulation of the RAS/RAF/MEK/extracellular signal regulated kinase (ERK) pathway plays a key role in the pathogenesis of several human cancers (5-8); mutations at upstream membrane receptors, NRAS and BRAF, as well as genes in other pathways [e.g., phosphatidylinositol 4,5-bisphosphate 3-kinase catalytic subunit alpha (PIK3CA), phosphatase and tensin homolog (PTEN) and AKT], which serve to regulate Raf activity, promote constitutive ERK signalling, stimulating proliferation and survival and providing essential tumour growth and maintenance functions (9). In melanoma, both the RAS-RAF-MEK-ERK (MAPK) and the PI3K-AKT (AKT) signalling pathways are constitutively activated through multiple mechanisms (9). Mutations of the BRAF gene have been proposed to contribute to the development of melanoma (10-12). The increased activity of the MAPK pathway prevents apoptosis and induces cell cycle progression (13). The most frequent BRAF mutation, which accounts for $<60 \%$ of melanoma tumours with BRAF activation, is a glutamic acid for valine substitution at codon 600 in exon 15, (Val600Glu; $\left.\mathrm{BRAF}^{\mathrm{V} 600 \mathrm{E}}\right)(9)$.

The melanoma microenvironment is a dynamic system, largely orchestrated, not only by malignant cells, but also from the stroma, that includes inflammatory cells, immune cells, fibroblasts, soluble molecules and the surrounding extracellular 
matrix (ECM) $(14,15)$. The perturbations of this network may interfere directly or indirectly with melanocyte-keratinocyte and/or melanocyte-ECM relationships and may impact on melanoma diagnosis, prognosis and treatment. Melanomagenesis requires the cooperation of several molecules playing a role in the tumour microenvironment (16-18).

In this context, the ECM plays an active role during melanoma progression, promoting the epigenetic transdifferentiation of melanocytes toward an invasive melanoma cell-like phenotype $(19,20)$. The invasion of tumour cells is a complex multistage process that includes proteolysis in the pericellular and stromal compartments, and has been shown to largely contribute to altering the tumour microenvironment, essential in promoting melanoma invasion, the degradation of basement membranes and remodeling of the ECM by proteolytic enzymes, such as matrix metalloproteinases (MMPs). MMPs, particularly MMP-2 and MMP-9 play a major role in the regulation of cancer cell migration, ECM invasion and metastasis through autocrine or paracrine pathways $(21,22)$. The expression of MMP-9 has been shown to be associated withthe intragenic hypermethylation of the MMP-9 gene in melanoma (23). Furthermore, its expression is regulated by lymphocytes and monocytes activated mostly at the transcriptional level by a variety of growth factors, cytokines and chemokines (24-26).

Numerous studies have suggested that the overexpression of MMP-2 and MMP-9 is associated with an aggressive behaviour, dissemination, advanced stages and poor prognosis in various types of cancer, including melanoma (22,26-35). Their activation in human cancer may be associated with the release of osteopontin (OPN), a secreted multifunctional phosphoprotein that has been implicated as an important mediator of tumour metastasis (36-39). Several reports have indicated that OPN, a matricellular protein found in the tumour microenvironment and expressed by host and cancer cells, may regulate tumourigenesis, cancer progression and metastasis (40-42).

In detail, OPN expression has been linked to tumourigenesis and metastasis in a wide range of cancers, including melanoma (43-48). Previous studies have suggested a role for increased OPN tissue expression in the malignant transformation of melanocytes, and as an important determinant of melanoma progression $(49,50)$. The aggressiveness of malignant melanoma has been associated with a high OPN expression and its overexpression correlates with advanced tumour stages $(50,51)$. OPN enhances the migration and invasion of malignant tumour cells possibly through both the inhibition of apoptosis and by regulating the activities of MMP-2 and MMP-9, which degrade the $\operatorname{ECM}(36,38,39)$.

Previous experimental data have suggested that in melanoma cell lines, OPN upregulates MMP-9 activity, modulating multiple signalling pathways via focal adhesion kinase (FAK), ERK and nuclear factor- $\kappa \mathrm{B}(\mathrm{NF}-\kappa \mathrm{B})(52-56)$ that regulate cytoskeletal organization, cell motility, cell growth, and ultimately control cell migration, ECM invasion and tumour growth (36).

In this context, it has been indicated that NF- $\kappa \mathrm{B}$ may be a key player in OPN and MMP-9 activation. However, whether $\mathrm{NF}-\kappa \mathrm{B}$ plays a role in the development and progression melanoma of in association with the OPN/MMP-9 axis according to the BRAF ${ }^{\mathrm{V} 600 \mathrm{E}}$ mutation status has not been investigated in detail to date. Thus, in the present study, OPN/MMP-9 pathway activation was examined in patients with melanoma, particularly those harbouring $\mathrm{BRAF}^{\mathrm{V} 600 \mathrm{E}}$ mutations. Furthermore, OPN/MMP-9 inhibition was observed in peripheral blood mononuclear cells (PBMCs) isolated from patients with melanoma following treatment with NF- $\mathrm{BB}$ inhibitor.

\section{Materials and methods}

Plasma samples from 148 patients with melanoma at different stages of the disease were collected for use in the present study. Samples were obtained prior to surgery, and were collected from the Unit of Dermatology, University of Messina (Messina, Italy) and stored until analyses at the Department of Biomedical and Biotechnological Sciences, University of Catania (Catania, Italy). Tumour samples from all patients were grouped according to the mutation status of $\mathrm{BRAF}^{\mathrm{V} 600 \mathrm{E}}$. The number of patients with melanoma harbouring the $\mathrm{BRAF}^{\mathrm{V} 600 \mathrm{E}}$ mutation was 86 , and the remaining 62 patients were BRAF $^{\mathrm{WT}}$. PBMCs were obtained from 29 patients with melanoma harbouring the $\mathrm{BRAF}^{\mathrm{V} 600 \mathrm{E}}$ mutation. As the control group, PBMCs and plasma samples from 53 healthy subjects were obtained and stored. Another set of plasma samples from 18 out of the 148 patients with melanoma was obtained at 3 months following surgery. The scientific Ethics Committee of the Policlinic University of Messina (Messina, Italy) approved all the procedures. All participants provided written consent prior to blood collection. Blood was centrifuged $\left(300 \mathrm{x}\right.$ g for $10 \mathrm{~min}$ at $4^{\circ} \mathrm{C}$ ) and the separated plasma was placed in aliquots and stored at $-80^{\circ} \mathrm{C}$ until analysis.

Plasma assays of OPN and MMP-9. The OPN and MMP-9 plasma concentrations were measured using ELISA kits (R\&D Systems Europe, Ltd., Abingdon, UK). The MMP-9 assays recognised both pro- and active forms. Plasma samples were diluted and the immunoassay was performed according to the instructions of the manufacturer. All assays were carried out in triplicate. The minimum detectable dose of OPN and MMP-9 was $<0.024$ and $0,156 \mathrm{ng} / \mathrm{ml}$, respectively. The optical density was measured at $450 \mathrm{~nm}$ using a microplate reader (Thermo Labsystems, Santa Rosa, CA, USA). The activities of MMP-9 were measured using specific Biotrak MMP-9 activity assay kits [Amersham Pharmacia Biotech (UK) Ltd., Little Chalfont, UK] according to the manufacturer's instructions. The appropriate standards were included in each assay. In order to measure the total content of the MMPs, the activation of the pro-form of the MMPs was performed using p-aminophenylmercuric acetate (APMA; Sigma-Aldrich Co. LLC. St. Louis, MO, USA).

Chemicals. Dehydroxymethylepoxyquinomycin (DHMEQ), a new NF- $\kappa$ B inhibitor, kindly provided by Professor Kazuo Umezawa (Keio University, Kanagawa, Japan), was synthesised as previously described (57). All other chemicals were purchased from Sigma-Aldrich Co. (Milan, Italy).

Isolation of PBMCs and analysis of $N F-\kappa B$ p65 activity and MMP-9 production. PBMCs were obtained using a Ficoll gradient. Following isolation, PBMC pellets were collected and stored immediately at $-80^{\circ} \mathrm{C}$ until analysis. PBMCs $\left(1 \times 10^{6}\right.$ cells $\left./ \mathrm{ml}\right)$, from patients with melanoma and 
healthy controls, were cultured in RPMI-1640 medium supplemented with $1 \%$ fetal calf serum (FCS), $2 \mathrm{mM}$ L-glutamine, $100 \mathrm{IU} / \mathrm{ml}$ penicillin and $100 \mu \mathrm{g} / \mathrm{ml}$ streptomycin (Gibco Life Technologies, Carlsbad, CA, USA). MMP-9 and NF-кB p65 activity was analysed in the supernatants and nuclear extract of PBMCs isolated from 29 patients with melanoma harbouring the BRAF ${ }^{\mathrm{V} 600 \mathrm{E}}$ mutation and 53 control patients. The PBMCs (following overnight incubation in serum-free medium) were stimulated with or without $100 \mathrm{ng} / \mathrm{ml}$ of recombinant human OPN (R\&D Systems, Inc., Minneapolis, MN, USA) for $24 \mathrm{~h}$ (each experimental condition was carried out in triplicate), with or without pre-incubation (1 h) with DHMEQ $(10 \mu \mathrm{g} / \mathrm{ml})$. The concentration of MMP-9 was determined using the human MMP-9 ELISA kit (R\&D Systems, Inc.) following the short-term culture of the isolated PBMCs.

For the measurement of NF- $\kappa \mathrm{B}$ activation, nuclear fractions were prepared from the PBMCs $\left(5-7 \times 10^{6}\right.$ cells per extraction) during batch processing using a Nuclear Extract kit (Active Motif, Rixensart, Belgium). The binding of NF- $\kappa \mathrm{B}$ to its consensus DNA sequence was measured by ELISA using a Trans-AM ${ }^{\mathrm{TM}}$ NF- $\mathrm{B}$ p65 Transcription Factor Assay kit (Active Motif), according to the instructions of the manufacturer. Briefly, nuclear extract protein (5 $\mu \mathrm{g} /$ well) was incubated in 96-well plates coated with immobilised oligonucleotide (5'-AGTTGAGGGGACTTTCCCAGGC-3') containing a consensus (5'-GGGACTTTCC-3') binding site for the p65 subunit of $N F-\kappa B$. NF- $\kappa \mathrm{B}$ binding to the target oligonucleotide was detected by incubation with primary antibody specific for the activated form of p65 (Active Motif; Cat.no. 40096), visualised by anti-IgG horseradish peroxidaseconjugated secondary antibody (Active Motif; Cat. no. 15015). At the end of the incubation period, the developing and stop solution were added, and an optical density of $450 \mathrm{~nm}$ (OD 450) was read on a Wallac Victor 1420 multilabel counter (PerkinElmer, Inc., Shelton, CT, USA).

Statistical analysis. The statistical methods have been previously reported in detail in the study by Polesel et al (57). Briefly, the values of plasma OPN, MMP-9 and MMP-9 activity were described as the median, minimum and maximum values. Differences in the distribution of OPN, MMP-9 and MMP-9 activity between the healthy controls and the melanoma cases were examined using a non-parametric Wilcoxon test or non-parametric $\chi^{2}$ tests. Correlations between markers were evaluated by means of Pearson's correlation scores. Odds ratios (ORs) and the corresponding 95\% confidence intervals (CIs) were calculated using the multiple logistic regression models adjusted for gender and age. A two-tailed value of $\mathrm{P}<0.05$ was considered to indicate a statistically significant difference. One-way ANOVA was also used to compare the OPN, MMP-9 and MMP-9 levels in the patients with melanoma who were $\mathrm{BRAF}^{\mathrm{WT}}$ and $\mathrm{BRAF}^{\mathrm{MUT}}$ according to the clinicopathological characteristics.

\section{Results}

The socio-demographic characteristics of the cases and the controls, and the distribution of melanoma cases according to clinical characteristics at diagnosis, are presented in Table I. The majority of cases were nodular melanoma (54\%),
Table I. Distribution of 148 melanoma cases 53 healthy controls according to sociodemografic variables and main clinical characteristics.

\begin{tabular}{|c|c|c|c|}
\hline & $\begin{array}{c}\text { Melanoma } \\
\text { cases }\end{array}$ & Controls & \\
\hline Characteristics & No. $(\%)$ & No. $(\%)$ & $\chi^{2}$ \\
\hline \multicolumn{4}{|l|}{ Gender } \\
\hline Male & $90(60.8)$ & $25(47.2)$ & \\
\hline Female & $58(39.2)$ & $28(52.8)$ & $\mathrm{P}=0.09$ \\
\hline \multicolumn{4}{|l|}{ Age, years } \\
\hline$<50$ & $32(21.6)$ & $27(50.9)$ & \\
\hline $50-59$ & $52(35.1)$ & $18(34.0)$ & \\
\hline$\geq 60$ & $64(43.2)$ & $8(15.1)$ & $\mathrm{P}<0.01$ \\
\hline \multicolumn{4}{|l|}{ Hystological subtype } \\
\hline Suderficially spreading & $68(46.0)$ & & \\
\hline Nodular & $80(54.0)$ & & \\
\hline \multicolumn{4}{|l|}{ Breslow thickness, mm } \\
\hline$\leq 2.0$ & $73(49.3)$ & & \\
\hline $2.1-4.0$ & $42(28.4)$ & & \\
\hline$>4.0$ & $33(22.3)$ & & \\
\hline \multicolumn{4}{|l|}{ Clark's level } \\
\hline $\begin{array}{l}\text { 2. Invasion of basal } \\
\text { layer epidermis }\end{array}$ & $64(43.2)$ & & \\
\hline $\begin{array}{l}\text { 3. Invasion of } \\
\text { papillary dermis }\end{array}$ & $58(39.2)$ & & \\
\hline $\begin{array}{l}\text { 4. Invasion of } \\
\text { reticular dermis }\end{array}$ & $14(9.5)$ & & \\
\hline $\begin{array}{l}\text { 5. Invasion of } \\
\text { subcutaneous fat }\end{array}$ & $12(8.1)$ & & \\
\hline \multicolumn{4}{|l|}{ Ulcerated lesion } \\
\hline No & $82(55.4)$ & & \\
\hline Yes & $61(41.2)$ & & \\
\hline Not evaluated & $5(3.4)$ & & \\
\hline \multicolumn{4}{|l|}{ Sentinel lymphonode } \\
\hline Negative & $93(62.8)$ & & \\
\hline Positive & $55(37.2)$ & & \\
\hline \multicolumn{4}{|l|}{ BRAF } \\
\hline Wild-type & $62(41.9)$ & & \\
\hline Mutated & $86(58.1)$ & & \\
\hline
\end{tabular}

without ulcerations (55.4\%), and with negative sentinel lymph nodes $(62.8 \%)$. Breslow thickness was $>4 \mathrm{~mm}$ for 33 cases $(22.3 \%)$ and the invasion of the reticular dermis or subcutaneous fat had occurred in $17.6 \%$ of cases.

Plasma levels of OPN and MMP-9. The plasma levels of OPN, MMP-9 and MMP-9 activity are shown in Fig. 1. For all considered markers, the levels were considerably higher among the melanoma cases than the healthy controls, particularly for those who had a positive sentinel lymph node and nodular histotype (Fig. 1). Table II shows the mean concentrations of 

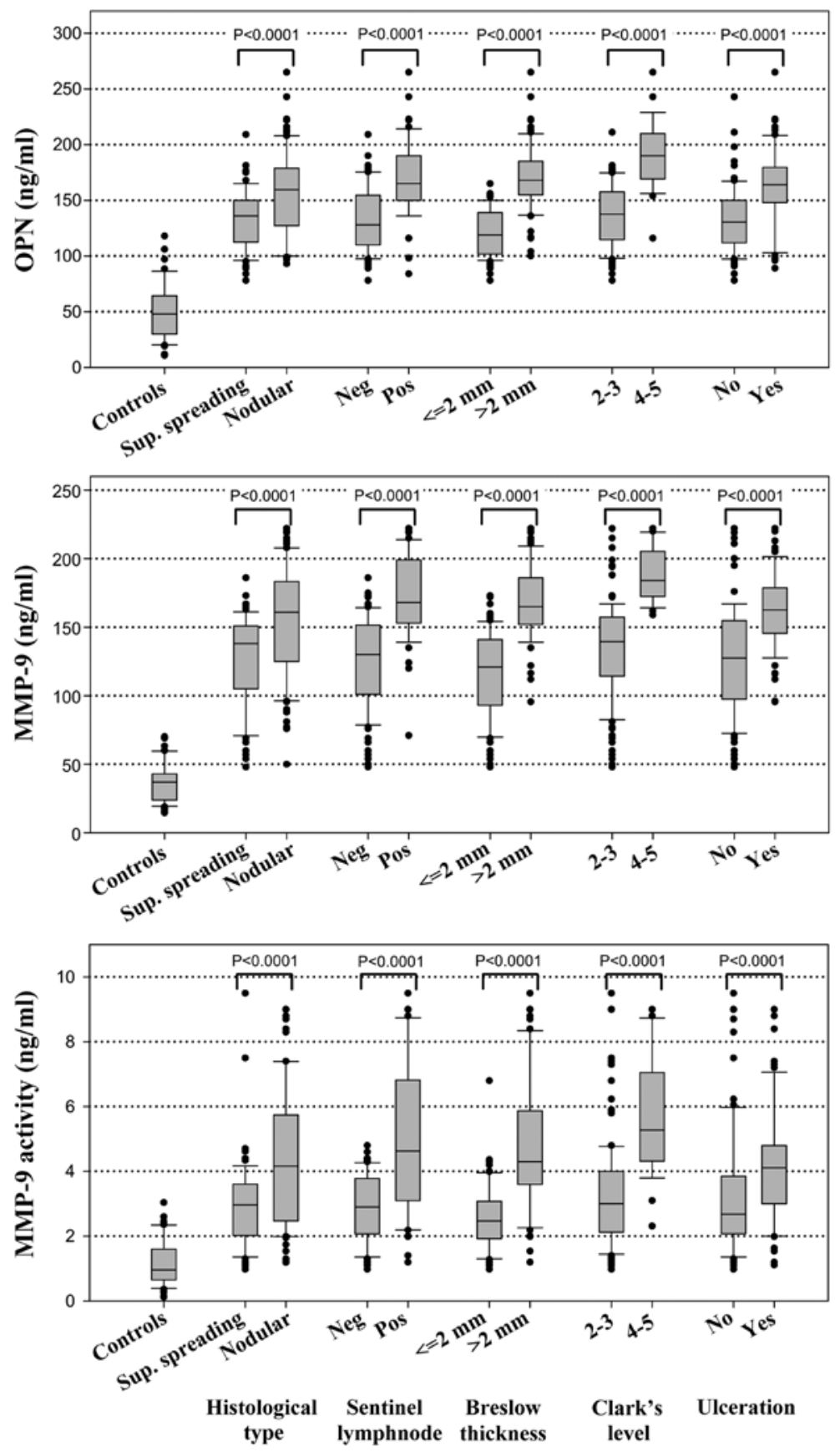

Figure 1. Distribution of osteopontin (OPN), matrix metalloproteinase (MMP)-9, and MMP-9 activity markers among 53 controls and 148 melanoma cases, according to clinicopathological characteristics. Neg, negative; Pos, positive.

these proteins according to the BRAF ${ }^{\mathrm{V} 600 \mathrm{E}}$ status. Higher levels of MMP-9 and MMP-9 activity were detected among the melanoma samples harbouring the $\mathrm{BRAF}^{\mathrm{V} 600 \mathrm{E}}$ mutation compared to those which were BRAF ${ }^{\mathrm{WT}}$; however, no significant differences were observed in the OPN levels between these two groups of patients (Table II). As expected, higher MMP-9 levels were also associated with other negative prognostic factors, such as sentinel lymph node involvement, Breslow thickness, Clark's level and ulceration (Table II). Linear correlations between OPN, MMP-9 and MMP-9 activity were high (r>0.50) among both melanoma cases and healthy subjects (Fig. 2).

The OPN and MMP-9 plasma levels, and MMP-9 activity were monitored in 18 melanoma cases who were followed-up actively (Table III). At cancer diagnosis, the levels of the three markers were 3- to -6-fold higher in the patients with melanoma than in the healthy controls. However, at 3 months post-surgery, the levels of OPN and MMP-9, and MMP-9 activity were significantly decreased and were comparable to those of the healthy controls. Of note, the melanoma cases with a positive sentinel lymph node maintained a higher expression of OPN than the negative ones (45.6 and 34.3, respectively) (Table III). Furthermore, in 3 patients with melanoma with the documented progression of disease after 3 months from the first surgery, the mean values of all markers increased (data not shown).

Production of $O P N$ and $M M P-9$ and $N F-\kappa B$ p65 activity from $P B M C s$. As PBMCs are the main source of the production of both OPN and MMP-9 $(39,59,60)$, we then determined the 
Table II. Mean concentration of OPN and MMP-9, and MMP-9a anctivity in 148 cases of menaloma according to clinopathological characteristics.

\begin{tabular}{|c|c|c|c|c|c|c|}
\hline & \multicolumn{2}{|c|}{ OPN } & \multicolumn{2}{|c|}{ MMP-9 } & \multicolumn{2}{|c|}{ MMP-9 activity } \\
\hline & $\mathrm{BRAF}^{\mathrm{WT}}$ & $\mathrm{BRAF}^{\mathrm{MUT}}$ & $\mathrm{BRAF}^{\mathrm{WT}}$ & $\mathrm{BRAF}^{\mathrm{MUT}}$ & $\mathrm{BRAF}^{\mathrm{WT}}$ & $\mathrm{BRAF}^{\mathrm{MUT}}$ \\
\hline Overall & 142.7 & 148.5 & 128.0 & $154.1^{\mathrm{d}}$ & 2.93 & $4.21^{\mathrm{d}}$ \\
\hline \multicolumn{7}{|l|}{ Hystological type } \\
\hline Superficial spreading & 134.1 & 131.4 & 121.0 & 133.3 & 2.39 & $3.33^{\mathrm{c}}$ \\
\hline Nodular & 150.7 & 162.1 & 134.5 & $170.6^{\mathrm{d}}$ & 3.44 & $4.91^{\mathrm{c}}$ \\
\hline \multicolumn{7}{|l|}{ Sentinel lymph node } \\
\hline Negative & 131.8 & 132.8 & 118.3 & $133.1^{\mathrm{b}}$ & 2.56 & $3.12^{\mathrm{c}}$ \\
\hline Positive & 171.5 & 168.4 & 153.6 & $180.6^{c}$ & 3.90 & $5.59^{\mathrm{b}}$ \\
\hline \multicolumn{7}{|l|}{ Breslow thickness } \\
\hline$\leq 2 \mathrm{~mm}$ & 124.9 & 116.8 & 114.6 & 119.8 & 2.42 & 2.81 \\
\hline$>2 \mathrm{~mm}$ & 177.5 & $167.3^{\mathrm{b}}$ & 154.1 & $174.4^{\mathrm{d}}$ & 3.93 & $5.05^{\mathrm{b}}$ \\
\hline \multicolumn{7}{|l|}{ Clark's level } \\
\hline $2-3$ & 137.2 & 135.6 & 124.1 & $142.1^{\mathrm{c}}$ & 2.77 & $3.69^{\mathrm{c}}$ \\
\hline $4-5$ & 221.5 & $186.2^{\mathrm{b}}$ & 183.5 & 189.0 & 5.30 & 5.74 \\
\hline \multicolumn{7}{|l|}{ Ulceration } \\
\hline No & 129.5 & 135.4 & 116.4 & $136.8^{\mathrm{b}}$ & 2.60 & $3.74^{\mathrm{c}}$ \\
\hline Yes & 161.9 & 163.3 & 144.8 & $174.8^{\mathrm{d}}$ & 3.40 & $4.87^{\mathrm{c}}$ \\
\hline
\end{tabular}

${ }^{\text {a }}$ Differences were examined by ANOVA, accounting for gender and age. Significance levels are indicated as follows: ${ }^{\mathrm{b}}<0.05 ;{ }^{\mathrm{c}}<0.01 ;{ }^{\mathrm{d}}<0.001$. OPN, osteopontin; MMP-9, matrix metalloproteinase-9.
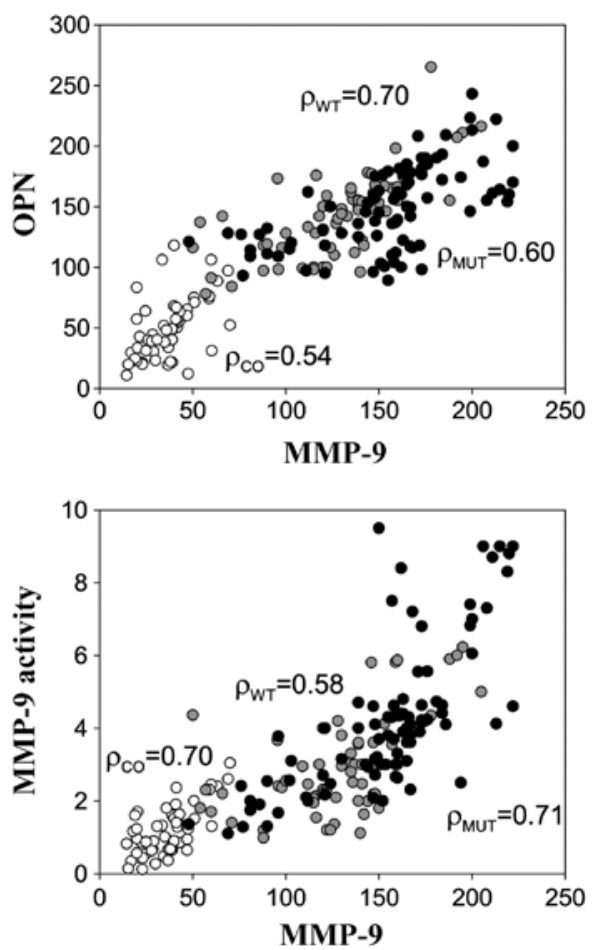

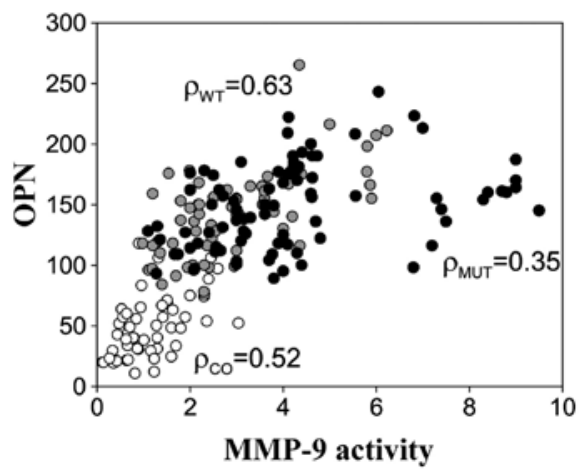

- Controls

- Melanoma cases BRAF ${ }^{\mathrm{WT}}$

- Melanoma cases BRAF ${ }^{\text {MUT }}$

Figure 2. Correlations between the expression of osteopontin (OPN) and matrix metalloproteinase (MMP)-9, and MMP-9 activity among the controls and melanoma cases according to BRAF mutation status. Linear correlations were evaluated through Pearson's correlation score (Q).

production of OPN and MMP-9 in PBMCs from 53 healthy donors and 29 patients with melanoma that were cultured for
$24 \mathrm{~h}$ with or without OPN. The secretion levels of OPN and MMP-9 in the supernatants of the PBMCs from the patients 
Table III. Mean values and standrd deviation (SD) of OPN and MMP-9 levels, and MMP-9 activity in 53 controls and 18 melanoma cases at diagnosis and at 3 months post-surgery.

\begin{tabular}{lrrr}
\hline & \multicolumn{2}{c}{$\begin{array}{c}\text { Time of markes } \\
\text { evaluation (mean } \pm \text { SD) }\end{array}$} \\
\cline { 3 - 4 } Marker & No. & \multicolumn{1}{c}{$\begin{array}{c}\text { At } \\
\text { enrolment }\end{array}$} & $\begin{array}{l}\text { At 3 months } \\
\text { post-surgery }\end{array}$ \\
\hline OPN & & & \\
$\quad$ Controls & 53 & $42.3(25.3)$ & \\
$\quad$ Melanoma, SL Neg & 4 & $189.0(14.6)$ & $34.3(14.5)$ \\
Melanoma, SL Pos & 14 & $208.1(25.5)$ & $45.6(15.8)$ \\
MMP-9 & & & \\
$\quad$ Controls & 53 & $36.6(14.2)$ & \\
Melanoma, SL Neg & 4 & $162.6(31.3)$ & $30.0(9.0)$ \\
$\quad$ Melanoma, SL Pos & 14 & $186.6(17.7)$ & $31.4(10.9)$ \\
MMP-9 activity & & & \\
$\quad$ Controls & 53 & $1.18(0.69)$ & \\
Melanoma, SL Neg & 4 & $3.52(1.32)$ & $1.14(0.48)$ \\
Melanoma, SL Pos & 14 & $5.65(1.33)$ & $1.40(0.57)$ \\
\hline
\end{tabular}

SL, sentinel lymphnode; OPN, osteopontin; MMP-9, matrix metalloproteinase-9; SL Neg, sentinel lymph node negative; SL Pos, sentinel lymph node positive.

Table IV. OPN, MMP-9, NF- $\mathrm{kB}$ basal values in PBMCs from the controls and patients with melanoma.

\begin{tabular}{lcr}
\hline PBMCs & Controls & Melanoma \\
\hline OPN ng/ml & $0.93 \pm 0.48$ & $8.4 \pm 3.5$ \\
MMP-9 ng/ml & $2.5 \pm 1.1$ & $13.1 \pm 3.7$ \\
NF- $\mathrm{kB}$ p65 activity & $0.15 \pm 0.05$ & $0.8 \pm 0.2$ \\
\hline
\end{tabular}

OPN, osteopontin; MMP-9, matrix metalloproteinase-9; NF-кB, nuclear factor- $\mathrm{kB}$; PBMCs, peripheral blood mononuclear cells.

with melanoma and healthy donors showed the same trend to those obtained in plasma (Table IV).

PBMCs from both the patients with melanoma and the controls were treated with OPN in order to determine the direct association with the increase in the MMP-9 levels in the supernatant. As expected, following treatment with OPN, the levels of MMP-9 were higher in the patients with melanoma than in the controls (Fig. 3A). A similar trend was observed by analysing the activity of NF- $\mathrm{KB}$ p65 (Fig. 3B). The PBMCs from the patients with melanoma and the controls were treated with the inhibitor of NF- $\mathrm{kB}$ (DHMQ) to demonstrate its effect on OPN, MMP-9 and NF-kB (Fig. 4). The results revealed that treatment with DHMQ did not affect the release of OPN, MMP-9 and NF- $\mathrm{kB}$ p65 activity in the PBMCs from healthy donors, whereas a significant decrease in the levels each protein was observed in the PBMCs from the patients with melanoma (Fig. 4). The PBMCs from the patients with
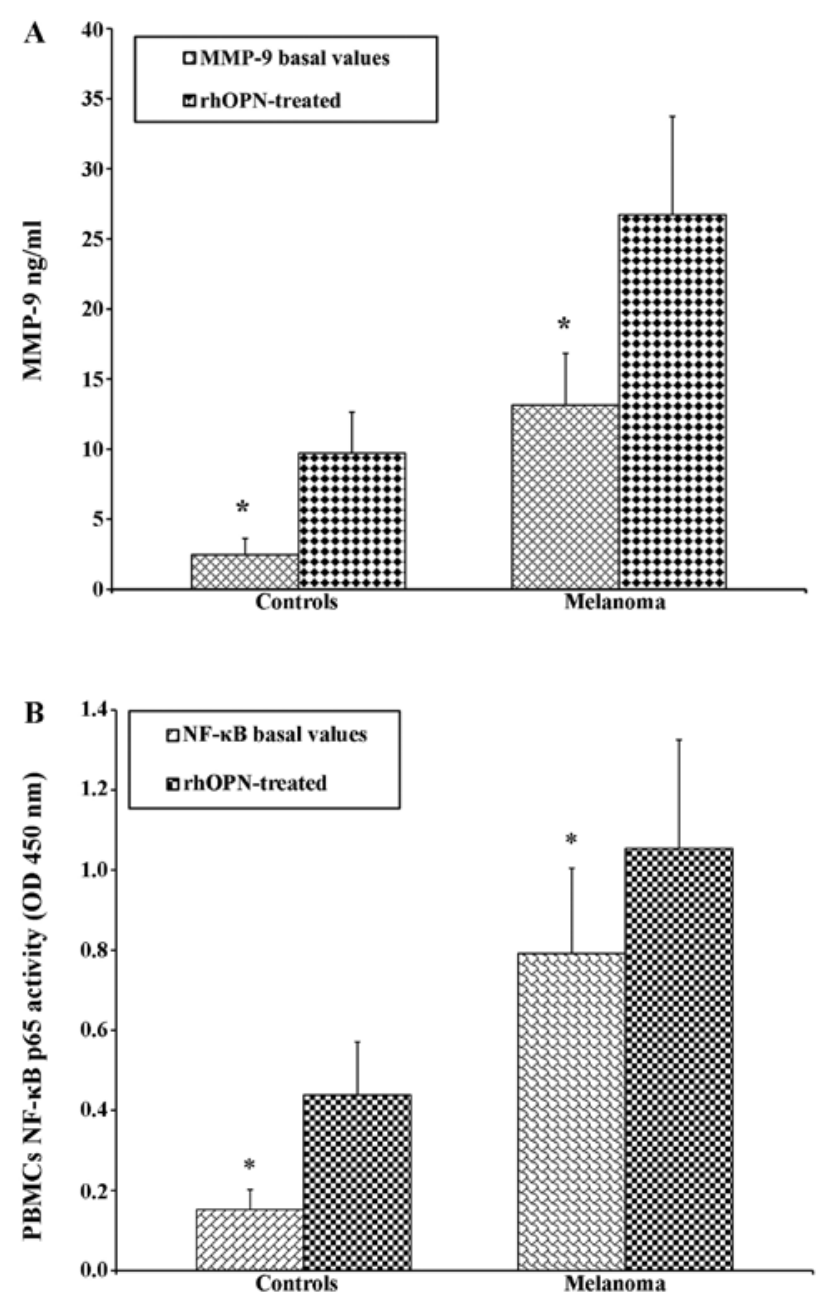

Figure 3. Secretion of (A) matrix metalloproteinase (MMP)-9 and (B) nuclear factor- $\mathrm{KB}(\mathrm{NF}-\mathrm{\kappa} \mathrm{B}) \mathrm{p} 65$ activity in peripheral blood mononuclear cells (PBMCs) from healthy donors and melanoma cases following treatment with recombinant human osteopontin (rhOPN). The levels of both (A) MMP-9 and (B) NF- $\mathrm{kB}$ p65 activity were higher in patients with melanoma than in the controls. ${ }^{*} \mathrm{P}<0.05$ compared to the rhOPN-treated cells. OD, optical density.

melanoma and the healthy controls were also treated with both OPN and DHMQ in order to examine their effects on MMP-9 and NF- $\mathrm{kB}$. In this case, the MMP-9 release and NF- $\mathrm{KB}$ p65 activity were markedly decreased in the PBMCs from both the controls and patients with melanoma (Fig. 4). In parallel, MMP-9 and NF- $\mathrm{KB}$ p65 activity were measured in PBMCs from patients with melanoma with or without $\mathrm{BRAF}^{\mathrm{V} 600 \mathrm{E}}$ mutation. The results revealed that both NF- $\mathrm{kB}$ p65 activity and MMP-9 release were higher in the PBMCs from patients with melanoma harbournig the $\mathrm{BRAF}^{\mathrm{V} 600 \mathrm{E}}$ mutation. Treatment with OPN further increased MMP-9 release and NF- $\mathrm{kB}$ p65 activity in both the controls and melanoma cases. The MMP-9 release and NF- $\mathrm{kB}$ p65 activity were both decreased following treatment with DHMEQ (Fig. 5).

\section{Discussion}

Melanoma is a complex process that involves the deregulation of interacting proteins and genes, which in turn are responsible for the proliferation, invasion, angiogenesis of tumour 

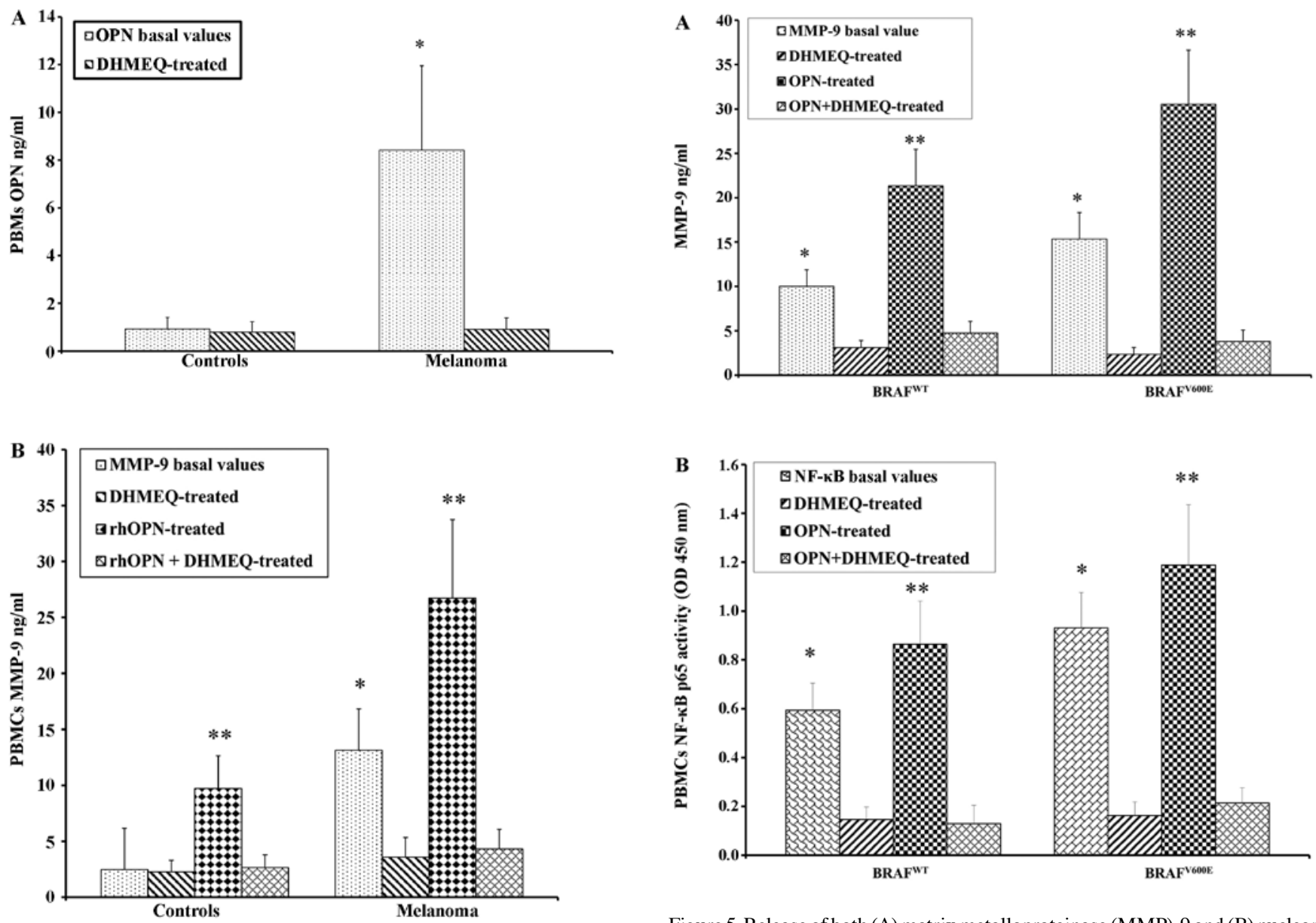

Figure 5. Release of both (A) matrix metalloproteinase (MMP)-9 and (B) nuclear factor- $\mathrm{\kappa B}(\mathrm{NF}-\mathrm{\kappa B})$ p65 activity in melanoma with or without $\mathrm{BRAF}{ }^{\mathrm{V} 600 \mathrm{E}}$ mutation. " $\mathrm{P}<0.05$ compared to DHMEQ-treated cells; ${ }^{* *} \mathrm{P}<0.05$ compared to

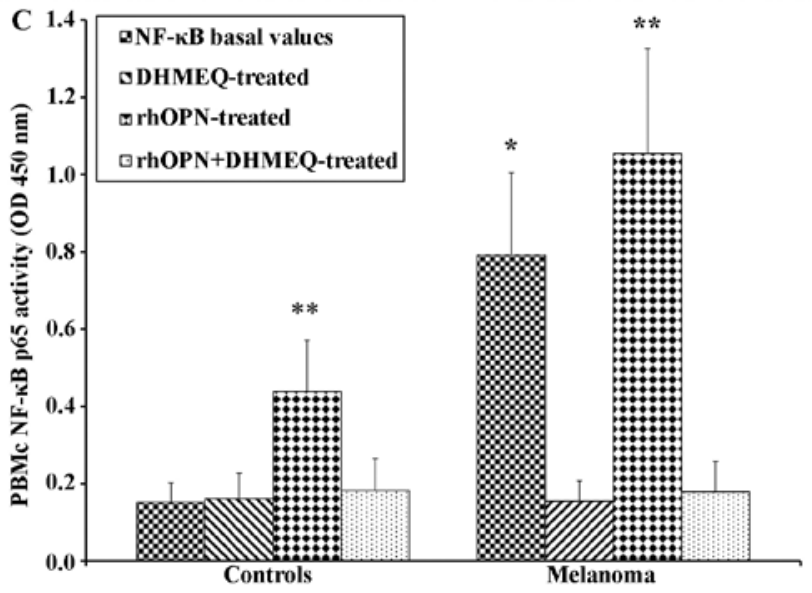
osteopontin (OPN) + DHMEQ-treated cells. OPN, osteopontin; OD, optical density; PBMCs, peripheral blood mononuclear cells.

Uncontrolled proliferation is a cancer hallmark, a result of the activation various oncogenic and angiogenic molecules, and of the crosstalk between many signalling pathways. Previous studies have strongly supported the crucial role of OPN in tumour progression through the regulation of multiple signalling events, including those critically dependent on MMP bioavailability (36-40,52-55). OPN contributes to aggressiveness both through the inhibition of apoptosis and the activation of various matrix-degrading proteases, such as the activation of MMP-2 and MMP-9 $(37,64)$. Although

Figure 4. Secretion of (A) osteopontin (OPN), (B) matrix metalloproteinase (MMP)-9 and (C) nuclear factor- $\mathrm{kB}$ (NF- $\mathrm{\kappa B}$ ), in PBMCs from healthy donors and melanoma cases treated with NF- $\mathrm{KB}$ inhibitor (DHMQ) treated with or without recombinant human osteopontin (rhOPN). "P<0.05 compared to DHMEQ-treated cells; ${ }^{* *} \mathrm{P}<0.05$ compared to rhOPN + DHMEQ-treated cells. OD, optical density; PBMCs, peripheral blood mononuclear cells.

cells, and finally the evasion of host immune systems (61). A prerequisite for melanoma progression, in addition to the ability of the cells to leave the cellular bond and to migrate, is the degradation of components of the ECM (62). Tumour cells and their microenvironment mutually influence each other during tumour development and progression (63). several studies have demonstrated that OPN and MMP-9 are implicated in the development and progression of several types of cancer $(22,34,35,38,43,46,49-51,65)$, it is important to investigate how these proteins may be involved in the molecular mechanism linked with melanoma development. Understanding such mechanisms may provide further insight into the discovery of novel therapeutic approaches.

The results of the present study, comprising the analysis of well-defined clinical material, including $>100$ blood samples from patients with melanoma, revealed a significant increase in OPN levels in the patients with melanoma compared to the heathy subjects. Furthermore, the highest levels of OPN were directly associated with ulceration, tumour thickness and nodular type. In melanoma, OPN expression is significantly 
associated with reduced survival and with a poor clinical outcome $(48,66)$.

In agreement with other reports demonstrating that MMP-9 is implicated in the regulation of tumour cell migration and in the development and metastasis $(22,26,27)$, our data indicated that higher MMP-9 levels, as well as OPN, are strongly associated with positive sentinel lymph-node and tumour thickness, markers of malignancy. A positive correlation between OPN and MMP-9, including MMP-9 activity, was found in both melanoma cases and healthy subjects.

Intriguingly, the levels of OPN and MMP-9 were monitored in 18 melanoma cases in a follow-up period of 3 months. Prior to surgery, these 18 cases expressed both markers at 3- to -6-fold higher levels than the healthy controls. At 3 months psotsurgery, these levels were significantly decreased. These results indicate the strong association of these molecules with the clinical manifestation of the disease. These data were confirmed by further experiments conducted on PBMCs from 53 healthy donors and 29 patients with melanoma that were cultured for $24 \mathrm{~h}$ with or without OPN. Stimulation of the PBMCs with OPN increased the production of MMP-9, particularly in the patients with melanoma. These data suggest that the OPN/MMP-9 pathway is associated with the transformation and progression of melanoma. The impact of OPN regulating MMP-9 is cell type-dependent and involves a variety of overlapping intracellular signalling pathways.

Therefore, the mechanism through which OPN mediates MMP-9 activation in melanoma and consequently enhances tumour aggressiveness may be associated with NF- $\kappa \mathrm{B}$ activation. OPN regulates MMP activity in various ways. It can bind MMP-9 and promote its activation through an NF- $\kappa \mathrm{B} / \mathrm{I} \kappa \mathrm{Ba} / \mathrm{IKK}$ signalling pathway (54). Accordingly, the treatment of PBMCs from healthy donors and patients with melanoma with OPN confirmed the production of $\mathrm{NF}-\kappa \mathrm{B}$ activity in patients with melanoma. NF- $\kappa \mathrm{B}$ activation has been connected with multiple processes of oncogenesis, including the control of apoptosis, cell cycle, differentiation and cell migration $(67,68)$. We have observed that the activity of the NF- $\mathrm{B}$ p65 subunit in PBMCs from patients with melanoma was higher when compared with that of the controls. We also evaluated the effect of DHMEQ, a specific inhibitor of NF- $\mathrm{B}(69-71)$, to determine whether NF- $\mathrm{B}$ inhibition was associated with the decrease of OPN and MMP-9 and to demonstrate the direct role of the NF- $\kappa \mathrm{B}$-regulated OPN and MMP-9 markers in patients with melanoma. Additional experiments with PBMCs from the two groups revealed that the MMP-9 levels decreased following treatment with both OPN and DHMEQ, suggesting a strong association between OPN and MMP-9 and their upregulation mediated by NF- $\kappa$ B. Intriguingly, such an activation was associated with melanoma diagnosed in patients harbouring the $\mathrm{BRAF}^{\mathrm{V} 600 \mathrm{E}}$ mutation. In the present study, through the analysis of each patient's medical file, $\mathrm{BRAF}^{\mathrm{V} 600 \mathrm{E}}$ mutation was detected in $58 \%$ of the patients with melanoma. The MMP-9 plasma levels were higher in the patients with such a mutation compared with those who were BRAFWT; furthermore, the association of higher plasma levels of MMP-9 with several negative prognostic factors supports the notion that MMP-9 may be implicated in the aggressiveness of melanoma.

Overall, the findings of the present study indicate that OPN and MMP-9 expression and their upstream regulator, $\mathrm{NF}-\kappa \mathrm{B}$, may be considered promising markers for melanoma development and may thus be useful targets for therapeutic interventions.

\section{Acknowledgements}

This study was in part supported by Lega Italiana per la Lotta contro i Tumori (LILT). We would like to thank Professor Kazuo Umezawa and the Kanagawa Keio University of Japan for providing the NF- $\kappa \mathrm{B}$ inhibitor.

\section{References}

1. Siegel RL, Miller KD and Jemal A: Cancer statistics, 2016. CA Cancer J Clin 66: 7-30, 2016.

2. Fava P, Astrua C, Chiarugi A, Crocetti E, Pimpinelli N, Fargnoli MC, Maurichi A, Rubegni P, Manganoni AM, Bottoni U, et al: Differences in clinicopathological features and distribution of risk factors in Italian melanoma patients. Dermatology 230: 256-262, 2015.

3. Russo A, Ficili B, Candido S, Pezzino FM, Guarneri C, Biondi A, Travali S, McCubrey JA, Spandidos DA and Libra M: Emerging targeted therapies for melanoma treatment (Review). Int $\mathbf{J}$ Oncol 45: 516-524, 2014.

4. Eggermont AM and Schadendorf D: Melanoma and immunotherapy. Hematol Oncol Clin North Am 23: 547-564, ix-x, 2009.

5. Caporali S, Alvino E, Lacal PM, Levati L, Giurato G, Memoli D, Caprini E, Antonini Cappellini GC and D'Atri S: Targeting the $\mathrm{PI} 3 \mathrm{~K} / \mathrm{AKT} / \mathrm{mTOR}$ pathway overcomes the stimulating effect of dabrafenib on the invasive behavior of melanoma cells with acquired resistance to the BRAF inhibitor. Int $\mathbf{J}$ Oncol 49: 1164-1174, 2016.

6. McCubrey JA, Steelman LS, Chappell WH, Abrams SL, Montalto G, Cervello M, Nicoletti F, Fagone P, Malaponte G, Mazzarino MC, et al: Mutations and deregulation of Ras/Raf/ MEK/ERK and PI3K/PTEN/Akt/mTOR cascades which alter therapy response. Oncotarget 3: 954-987, 2012.

7. Grazia G, Penna I, Perotti V, Anichini A and Tassi E: Towards combinatorial targeted therapy in melanoma: From pre-clinical evidence to clinical application (Review). Int J Oncol 45: 929-949, 2014.

8. McCubrey JA, Steelman LS, Chappell WH, Abrams SL, Wong EW, Chang F, Lehmann B, Terrian DM, Milella M, Tafuri A, et al: Roles of the Raf/MEK/ERK pathway in cell growth, malignant transformation and drug resistance. Biochim Biophys Acta 1773: 1263-1284, 2007.

9. Solus JF and Kraft S: Ras, Raf, and MAP kinase in melanoma. Adv Anat Pathol 20: 217-226, 2013.

10. Libra M, Malaponte G, Navolanic PM, Gangemi P, Bevelacqua V, Proietti L, Bruni B, Stivala F, Mazzarino MC, Travali S, et al: Analysis of BRAF mutation in primary and metastatic melanoma. Cell Cycle 4: 1382-1384, 2005.

11. Candido S, Rapisarda V, Marconi A, Malaponte G, Bevelacqua V, Gangemi P, Scalisi A, McCubrey JA, Maestro R, Spandidos DA, et al: Analysis of the $B-R a f^{\vee 600 \mathrm{E}}$ mutation in cutaneous melanoma patients with occupational sun exposure. Oncol Rep 31: 1079-1082, 2014.

12. Lin K, Baritaki S, Militello L, Malaponte G, Bevelacqua Y and Bonavida B: The Role of B-RAF Mutations in Melanoma and the Induction of EMT via Dysregulation of the NF-кB/Snail/RKIP/PTEN Circuit. Genes Cancer 1: 409-420, 2010.

13. Cantwell-Dorris ER, O'Leary JJ and Sheils OM: BRAFV600E: Implications for carcinogenesis and molecular therapy. Mol Cancer Ther 10: 385-394, 2011.

14. Mbeunkui F and Johann DJ Jr: Cancer and the tumor microenvironment: A review of an essential relationship. Cancer Chemother Pharmacol 63: 571-582, 2009.

15. Zhang $\mathrm{J}$ and Liu J: Tumor stroma as targets for cancer therapy. Pharmacol Ther 137: 200-215, 2013.

16. Bevelacqua V, Bevelacqua Y, Candido S, Skarmoutsou E, Amoroso A, Guarneri C, Strazzanti A, Gangemi P, Mazzarino MC, D'Amico F, et al: Nectin like-5 overexpression correlates with the malignant phenotype in cutaneous melanoma. Oncotarget 3: 882-892, 2012.

17. Whipple CA: Tumor talk: Understanding the conversation between the tumor and its microenvironment. Cancer Cell Microenviron 2: e773, 2015. 
18. Villanueva J and Herlyn M: Melanoma and the tumor microenvironment. Curr Oncol Rep 10: 439-446, 2008.

19. Seftor EA, Brown KM, Chin L, Kirschmann DA, Wheaton WW, Protopopov A, Feng B, Balagurunathan Y, Trent JM Nickoloff BJ, et al: Epigenetic transdifferentiation of normal melanocytes by a metastatic melanoma microenvironment. Cancer Res 65: 10164-10169, 2005.

20. Postovit LM, Seftor EA, Seftor RE and Hendrix MJ: Influence of the microenvironment on melanoma cell fate determination and phenotype. Cancer Res 66: 7833-7836, 2006.

21. Bauvois B: New facets of matrix metalloproteinases MMP-2 and MMP-9 as cell surface transducers: Outside-in signaling and relationship to tumor progression. Biochim Biophys Acta 1825: 29-36, 2012.

22. Stetler-Stevenson WG: The role of matrix metalloproteinases in tumor invasion, metastasis, and angiogenesis. Surg Oncol Clin N Am 10: 383-392, x, 2001

23. Falzone L, Salemi R, Travali S, Scalisi A, McCubrey JA, Candido S and Libra M: MMP-9 overexpression is associated with intragenic hypermethylation of MMP9 gene in melanoma. Aging (Albany NY) 8: 933-944, 2016.

24. Candido S, Abrams SL, Steelman LS, Lertpiriyapong K, Fitzgerald TL, Martelli AM, Cocco L, Montalto G, Cervello M, Polesel J, et al: Roles of NGAL and MMP-9 in the tumor microenvironment and sensitivity to targeted therapy. Biochim Biophys Acta 1863: 438-448, 2016.

25. Shellman YG, Makela M and Norris DA: Induction of secreted matrix metalloproteinase-9 activity in human melanoma cells by extracellular matrix proteins and cytokines. Melanoma Res 16: 207-211, 2006.

26. Roomi MW, Kalinovsky T, Rath $M$ and Niedzwiecki A: In vitro modulation of MMP-2 and MMP-9 in pediatric human sarcoma cell lines by cytokines, inducers and inhibitors. Int J Oncol 44: 27-34, 2014.

27. Heo DS, Choi H, Yeom MY, Song BJ and Oh SJ: Serum levels of matrix metalloproteinase-9 predict lymph node metastasis in breast cancer patients. Oncol Rep 31: 1567-1572, 2014.

28. Aalinkeel R, Nair BB, Reynolds JL, Sykes DE, Mahajan SD, Chadha KC and Schwartz SA: Overexpression of MMP-9 contributes to invasiveness of prostate cancer cell line $\mathrm{LNCaP}$ Immunol Invest 40: 447-464, 2011.

29. Chou CH, Teng CM, Tzen KY, Chang YC, Chen JH and Cheng JC: MMP-9 from sublethally irradiated tumor promotes Lewis lung carcinoma cell invasiveness and pulmonary metastasis Oncogene 31: 458-468, 2012

30. Malaponte G, Polesel J, Candido S, et al: IL-6-174 G > C and MMP-9-1562 C > T polymorphisms are associated with increased risk of deep vein thrombosis in cancer patients. Cytokine 62: 64-69, 2013.

31. Di Carlo A, Terracciano D, Mariano A and Macchia V: Matrix metalloproteinase-2 and matrix metalloproteinase-9 type IV collagenases in serum of patients with pleural effusions. Int $\mathrm{J}$ Oncol 26: 1363-1368, 2005.

32. Kato Y, Yamashita T and Ishikawa M: Relationship between expression of matrix metalloproteinase-2 and matrix metalloproteinase-9 and invasion ability of cervical cancer cells. Oncol Rep 9: 565-569, 2002

33. Mook OR, Frederiks WM and Van Noorden CJ: The role of gelatinases in colorectal cancer progression and metastasis. Biochim Biophys Acta 1705: 69-89, 2004

34. Malaponte G, Zacchia A, Bevelacqua Y, Marconi A, Perrotta R, Mazzarino MC, Cardile V and Stivala F: Co-regulated expression of matrix metalloproteinase-2 and transforming growth factor-beta in melanoma development and progression. Oncol Rep 24: 81-87, 2010.

35. Nikkola J, Vihinen P, Vuoristo MS, Kellokumpu-Lehtinen P, Kähäri VM and Pyrhönen S: High serum levels of matrix metalloproteinase-9 and matrix metalloproteinase-1 are associated with rapid progression in patients with metastatic melanoma. Clin Cancer Res 11: 5158-5166, 2005.

36. Chen YJ, Wei YY, Chen HT, Fong YC, Hsu CJ, Tsai CH, Hsu HC, Liu SH and Tang CH: Osteopontin increases migration and MMP-9 up-regulation via alphavbeta3 integrin, FAK, ERK, and NF-kappaB-dependent pathway in human chondrosarcoma cells. J Cell Physiol 221: 98-108, 2009.

37. Philip S, Bulbule A and Kundu GC: Osteopontin stimulates tumor growth and activation of promatrix metalloproteinase-2 through nuclear factor-kappa B-mediated induction of membrane type 1 matrix metalloproteinase in murine melanoma cells. J Biol Chem 276: 44926-44935, 2001
38. Castellano G, Malaponte G, Mazzarino MC, Figini M, Marchese F, Gangemi P, Travali S, Stivala F, Canevari S and Libra M: Activation of the osteopontin/matrix metalloproteinase-9 pathway correlates with prostate cancer progression. Clin Cancer Res 14: 7470-7480, 2008

39. Malaponte G, Hafsi S, Polesel J, Castellano G, Spessotto P, Guarneri C, Canevari S, Signorelli SS, McCubrey JA and Libra M: Tumor microenvironment in diffuse large B-cell lymphoma: Matrixmetalloproteinases activation is mediated by osteopontin overexpression. Biochim Biophys Acta 1863: 483-489, 2016.

40. Wai PY and Kuo PC: Osteopontin: Regulation in tumor metastasis. Cancer Metastasis Rev 27: 103-118, 2008.

41. Weber GF: The metastasis gene osteopontin: A candidate target for cancer therapy. Biochim Biophys Acta 1552: 61-85, 2001.

42. El-Tanani MK, Campbell FC, Kurisetty V, Jin D, McCann M and Rudland PS: The regulation and role of osteopontin in malignant transformation and cancer. Cytokine Growth Factor Rev 17: 463-474, 2006

43. Libra M, Indelicato M, De Re V, Zignego AL, Chiocchetti A, Malaponte G, Dianzani U, Nicoletti F, Stivala F, McCubrey JA, et al: Elevated Serum Levels of Osteopontin in HCV-Associated Lymphoproliferative Disorders. Cancer Biol Ther 4: 1192-1194, 2005.

44. Poruk KE, Firpo MA, Scaife CL, Adler DG, Emerson LL, Boucher KM and Mulvihill SJ: Serum osteopontin and tissue inhibitor of metalloproteinase 1 as diagnostic and prognostic biomarkers for pancreatic adenocarcinoma. Pancreas 42 : 193-197, 2013.

45. Wang YD, Chen H, Liu HQ and Hao M: Correlation between ovarian neoplasm and serum levels of osteopontin: A meta-analysis. Tumour Biol 35: 11799-11808, 2014.

46. Cao DX, Li ZJ, Jiang XO, Lum YL, Khin E, Lee NP, Wu GH and Luk JM: Osteopontin as potential biomarker and therapeutic target in gastric and liver cancers. World J Gastroenterol 18 3923-3930, 2012

47. Lin F, Li Y, Cao J, Fan S, Wen J, Zhu G, Du H and Liang Y: Overexpression of osteopontin in hepatocellular carcinoma and its relationships with metastasis, invasion of tumor cells. Mol Biol Rep 38: 5205-5210, 2011

48. Rangel J, Nosrati M, Torabian S, Shaikh L, Leong SP, Haqq C, Miller JR III, Sagebiel RW and Kashani-Sabet M: Osteopontin as a molecular prognostic marker for melanoma. Cancer 112: 144-150, 2008

49. Sturm RA: Osteopontin in melanocytic lesions - a first step towards invasion? J Invest Dermatol 124: xiv-xv, 2005.

50. Kiss T, Ecsedi S, Vizkeleti L, Koroknai V, Emri G, Kovács N, Adany R and Balazs M: The role of osteopontin expression in melanoma progression. Tumour Biol 36: 7841-7847, 2015.

51. Zhou Y, Dai DL, Martinka M, Su M, Zhang Y, Campos EI, Dorocicz I, Tang L, Huntsman D, Nelson C, et al: Osteopontin expression correlates with melanoma invasion. J Invest Dermatol 124: 1044-1052, 2005.

52. Matušan-Ilijaš K, Damante G, Fabbro D, Dorđević G, Hadžisejdić I, Grahovac M, Marić I, Spanjol J, Grahovac B, Jonjić N, et al: Osteopontin expression correlates with nuclear factor- $\mathrm{\kappa B}$ activation and apoptosis downregulation in clear cell renal cell carcinoma. Pathol Res Pract 207: 104-110, 2011.

53. Das R, Mahabeleshwar GH and Kundu GC: Osteopontin stimulates cell motility and nuclear factor kappaB-mediated secretion of urokinase type plasminogen activator through phosphatidylinositol 3-kinase/Akt signaling pathways in breast cancer cells. J Biol Chem 278: 28593-28606, 2003.

54. Rangaswami H and Kundu GC: Osteopontin stimulates melanoma growth and lung metastasis through NIK/MEKK1-dependent MMP-9 activation pathways. Oncol Rep 18: 909-915, 2007.

55. Rangaswami H, Bulbule A and Kundu GC: Nuclear factor-inducing kinase plays a crucial role in osteopontin-induced MAPK/IkappaBalpha kinase-dependent nuclear factor kappaB-mediated promatrix metalloproteinase- 9 activation. J Biol Chem 279: 38921-38935, 2004.

56. Liu J, Liu Q, Wan Y, Zhao Z, Yu H, Luo H and Tang Z Osteopontin promotes the progression of gastric cancer through the NF- $\kappa$ B pathway regulated by the MAPK and PI3K. Int J Oncol 45: 282-290, 2014.

57. Polesel J, Franceschi S, Talamini R, Negri E, Barzan L, Montella M, Libra M, Vaccher E, Franchin G, La Vecchia C and Serraino D: Tobacco smoking, alcohol drinking, and the risk of different histological types of nasopharyngeal cancer in a low-risk population. Oral Oncol 47: 541-545, 2011. 
58. Matsumoto N, Ariga A, To-e S, Nakamura H, Agata N, Hirano S, Inoue $\mathrm{J}$ and Umezawa K: Synthesis of NF-kappaB activation inhibitors derived from epoxyquinomicin C. Bioorg Med Chem Lett 10: 865-869, 2000.

59. Catalán V, Gómez-Ambrosi J, Rodríguez A, Ramírez B, Valentí V, Moncada R, Silva C, Salvador J and Frühbeck G: Peripheral mononuclear blood cells contribute to the obesity-associated inflammatory state independently of glycemic status: involvement of the novel proinflammatory adipokines chemerin, chitinase3 -like protein 1, lipocalin-2 and osteopontin. Genes Nutr 10: 460, 2015.

60. Buommino E, De Filippis A, Gaudiello F, Balato A, Balato N, Tufano MA and Ayala F: Modification of osteopontin and MMP-9 levels in patients with psoriasis on anti-TNF- $\alpha$ therapy. Arch Dermatol Res 304: 481-485, 2012.

61. Tímár J, Gyorffy B and Rásó E: Gene signature of the metastatic potential of cutaneous melanoma: Too much for too little? Clin Exp Metastasis 27: 371-387, 2010.

62. Brooks SA, Lomax-Browne HJ, Carter TM, Kinch CE and Hall DM: Molecular interactions in cancer cell metastasis. Acta Histochem 112: 3-25, 2010.

63. Hu M and Polyak K: Microenvironmental regulation of cancer development. Curr Opin Genet Dev 18: 27-34, 2008.

64. Rangaswami H, Bulbule A and Kundu GC: Nuclear factor inducing kinase: A key regulator in osteopontin- induced MAPK/IkappaB kinase dependent NF-kappaB-mediated promatrix metalloproteinase-9 activation. Glycoconj J 23: 221-232, 2006.
65. Rangaswami H, Bulbule A and Kundu GC: Osteopontin: Role in cell signaling and cancer progression. Trends Cell Biol 16: 79-87, 2006.

66. Mitra A, Conway C, Walker C, Cook M, Powell B, Lobo S, Chan M, Kissin M, Layer G, Smallwood J, et al: Melanoma sentinel node biopsy and prediction models for relapse and overall survival. Br J Cancer 103: 1229-1236, 2010.

67. Vlahopoulos SA, Cen O, Hengen N, Agan J, Moschovi M, Critselis E, Adamaki M, Bacopoulou F, Copland JA, Boldogh I, et al: Dynamic aberrant NF- $\mathrm{BB}$ spurs tumorigenesis: A new model encompassing the microenvironment. Cytokine Growth Factor Rev 26: 389-403, 2015.

68. Xia Y, Shen S and Verma IM: NF- $\kappa$ B, an active player in human cancers. Cancer Immunol Res 2: 823-830, 2014.

69. McCubrey JA, Milella M, Tafuri A, Martelli AM, Lunghi P, Bonati A, Cervello M, Lee JT and Steelman LS: Targeting the Raf/MEK/ERK pathway with small-molecule inhibitors. Curr Opin Investig Drugs 9: 614-630, 2008.

70. Gupta SC, Sundaram C, Reuter S and Aggarwal BB: Inhibiting NF- $\kappa B$ activation by small molecules as a therapeutic strategy. Biochim Biophys Acta 1799: 775-787, 2010.

71. Malaponte G, Signorelli SS, Bevelacqua V, Polesel J, Taborelli M, Guarneri C, Fenga C, Umezawa K and Libra M: Increased Levels of NF- $\kappa \mathrm{B}-$ Dependent Markers in Cancer-Associated Deep Venous Thrombosis. PLoS One 10: e0132496, 2015. 